\title{
MAGYAR CORVIN LÁNC UND MAGYAR CORVIN KOSZORÚ: ÜBER DEN URSPRUNG DES MODERNEN UNGARISCHEN LITERATURPREISSYSTEMS
}

\author{
ERIKA ERLINGHAGEN \\ Universität Wien. \\ erika.erlinghagen@univie.ac.at
}

\begin{abstract}
In Hinblick auf den von Viktor Orbán im Jahr 2001 neu, oder vielmehr: wieder eingeführten Staatspreis, die sogenannte Ungarische Corvin Kette (Magyar Corvin Lánc), beschäftigt sich der Artikel mit den Anfängen des modernen staatlichen Auszeichnungssystems in Ungarn, die im Ungarn der Zwischenkriegszeit zu verorten sind. Konkret wird auf die Entstehungs- und Vergabegeschichte der ursprünglich von Miklós Horthy gegründeten Staatspreise, namentlich der Ungarischen Corvin Kette sowie des Ungarischen Corvin Kranzes (Magyar Corvin Koszorú), eingegangen, wobei zur Einschränkung, aber insbesondere zur Exemplifizierung der hinter der Vergabe stehenden kulturpolitischen Strategien der Fokus der Betrachtungen auf den mit den Corvin-Preisen ausgezeichneten Literaten liegt. Damit soll der Anstoß zu einer kritischen Auseinandersetzung mit der 2001 wiedereingeführten Ungarischen Corvin Kette und deren Vergabepraktiken gegeben werden.
\end{abstract}

Schlüsselwörter: Staatliche Literaturpreise, Kulturpolitik, Literaturpolitik, Zwischenkriegszeit, Magyar Corvin Lánc, Magyar Corvin Koszorú, Kunó Klebelsberg, Ferenc Herczeg, Cecil Tormay

Im Zuge seiner ersten Regierungszeit als Ministerpräsident gründete Viktor Orbán die Magyar Corvin Lánc, die Ungarische Corvin Kette, als vom Ministerpräsident vergebene Auszeichnung ${ }^{1}$. Am 24. August 2001 wurde sie an den Atomphysiker Ede Teller, den Zoologen und Kossuth- sowie Széchenyi-Preisträger János Balogh, an den Ökonomen Sándor Lámfalussy, den Historiker János Lukács, den Architekten und Kossuth-Preisträger Imre Makovecz sowie die Schriftstellerin und Kossuth-Preisträgerin Magda Szabó vergeben. Am 1. Dezember desselben Jahres wurden zusätzlich der Chemiker und Nobelpreisträger György Oláh, der Mathematiker und Wolf-Preisträger László Lovász, der Volkskundler und Kossuth-Preisträger Zoltán Kallós, der Regisseur und Oscar-Preisträger Vilmos Zsigmond sowie der Komponist und Kossuth-Preisträger Sándor Szokolay mit der Ungarischen Corvin Kette ausgezeichnet. Diese 12 Personen stellten in Folge die Magyar Corvin-lánc Testület (Gremium der Ungarischen Corvin Kette), als deren Präsident István Nemeskürty gewählt wurde, die ausgewählten Talenten dreijährige Stipendien in der Höhe von monatlich 500.000 Forint zuzusprechen 
vermag. ${ }^{2}$ Auf der offiziellen Homepage der von Orbán 2010 in den Rang eines Staatspreises erhobenen Auszeichnung findet sich ein kurzer Abschnitt über die Geschichte des Preises - hier wird in einem Absatz auf die ursprünglichen, in der Zwischenkriegszeit von Miklós Horthy gegründeten Corvin-Preise, die Magyar Corvin Lánc (Ungarische Corvin Kette) und den Magyar Corvin Koszorú (Ungarischen Corvin Kranz), verwiesen. ${ }^{3}$ Eine etwas ausführlichere und vor allem auch kritische Auseinandersetzung mit dem historischen Vorläufer des von Orbán im Prinzip wiedereingeführten anstatt neu-gegründeten Preises fehlt. Der vorliegende Artikel möchte eine Möglichkeit aufzeigen, wie diese doch signifikante Lücke zu schließen wäre. ${ }^{4}$

\section{Über die Gründung der Ungarischen Corvin Kette und des Ungarischen Corvin Kranzes}

Nach der Niederlage im Ersten Weltkrieg hatte Ungarn aufgrund des Friedensvertrags von Trianon zwei Drittel seines Gebietes an seine Nachbarländer verloren und damit nicht nur wertvolle Teile der bis dahin aufgebauten wissenschaftlichen und kulturellen Institutionen sowie Bildungseinrichtungen, sondern auch einen beachtlichen Teil der Intellektuellenschicht. Der äußerst enge politische und wirtschaftliche Bewegungsspielraum des Kriegsverlierers ließ die ungarische politische Elite bald erkennen, dass die krisenhafte Situation des Landes nur auf dem Gebiet der Kultur, der Wissenschaft und der Bildung entschärft werden konnte. ${ }^{5}$ So kam der Kulturpolitik in der sich herausbildenden autokratischen politischen Struktur eine Schlüsselposition zu, wobei festgehalten werden muss, dass sie sich in jener Zeit in erster Linie um Bildungsfragen drehte. Während der gesamten Zwischenkriegszeit war sodann die Wiederherstellung des Territoriums des historischen Königreichs Ungarn das erklärte nationale Ziel und der Kultur- und vor allem der Bildungssektor sollten speziell zu Beginn zum primären Ersatz-Schlachtfeld werden - in den Augen der Regierung ...

\footnotetext{
„Szeretném a köztudatba belevinni, hogy a trianoni béke következetében lefegyverezett Magyarországon a kultusztárca voltaképpen honvédelmi tárca is. Honvédelmi tárca olyan értelemben, hogy most elsősorban a szellem, a művelődés fegyvereivel kell védeni a hazánkat, és ezekkel az eszközökkel kell mindig újból és újból bebizonyítanunk a világ nemzetei elött, hogy a magyar viszontagságos életének második ezer esztendejében is életképes, erős, és hogy bántani nagy történelmi igazságtalanság. “6
}

... wie auch im Bewusstsein der Bevölkerung. 
„Az iskolában már megtanultátok, hogy Nagy-Magyarország területe 325 ezer négyzetkilométer volt. A trianoni Magyarországé pedig csak 92 ezer négyzetkilométer: Tudjátok azt is, hogy Nagy-Magyarországon 21 millió ember lakott, a trianoni Magyarországnak ellenben csak 8 millió lakosa van. Majdnem egyharmadára zsugarodott össze a hazánk. Ha mindennek dacára sem akarjuk a nemzetek sorában elveszíteni azt a helyet, amelyet a magyarság korábban elfoglalt, akkor a mi munkánk eredményének legalább annyinak kell lennie, mint amennyit régebben a történeti Magyarország 21 millió lakosa végzett. De emelnünk kell nemzetünk belső értékét is, fokoznunk kell nemcsak az egyes ember teljesítőképességét külön-külön, hanem a nemzet együttes összmunkájának eredményét is. “7

Diese Worte stammen von Graf Kunó Klebelsberg, der sein Amt am 16. Juni 1922 antrat und dem Ministerium für Religion und Unterrichtswesen beinahe ein Jahrzehnt lang, bis 24. August 1931, vorstand. Klebelsberg rief das für diese Zeit entsprechende Motto in seiner Rede am 19. Juni 1922 anlässlich seines Amtsantritts aus: „Nekünk dolgozni kell és ne feledjük, hogy a magyar hazát ma első sorban nem a kard, hanem a kultúra tarthatja meg és teheti ismét naggyá."8

Klebelsbergs kulturpolitische Vision prägte das Gesicht Ungarns. So betonte er im Zusammenhang mit dem damals als ungerechten Schicksalsschlag empfundenen und bis dato als schweres Trauma im kollektiven Gedächtnis Ungarns verankerten „Friedensdiktat“" von Trianon, dass es dem Land nun die seit Jahrhunderten ersehnte Unabhängigkeit beschert habe, die es ihm möglich mache, neue Werte in der Kultur und damit ein neues, modernes Ungarn zu erschaffen, was Klebelsberg als überlebensnotwendigen Schritt betrachtete. ${ }^{9}$

\footnotetext{
„Ez idő alatt vált a kulturális megújulás olyan politikai programmá, amely a nemzeti érzés megerősítésében és újjáformálásában, az európai értékek megközelítésében találta meg értelmét. Bethlen István miniszterelnökkel azonos politikai meggyőződésének meghatározó eleme volt a 19. század végére kiépült liberális állami intézményrendszer védelme, a vagyonos és müvelt felsőbb társadalmi csoportok, leginkább az arisztokrácia és a birtokos nemesség elsőbbségének megörzése. Mindketten egy autoriter, erős államban gondolkodtak." 10
}

Um seinem Motto und der von ihm aufgezeigten Chance gerecht zu werden, schuf Klebelsberg einen konkreten kulturpolitischen Handlungsplan, der beachtliche kulturpolitische Maßnahmen nach sich zog. Die Förderung der Kultur und des kulturellen Lebens erwies sich in der Zwischenkriegszeit auch insofern als ideales Betätigungsfeld, weil die Bemühungen speziell im Bereich der Kunst und Literatur auch in den ungarischen Siedlungsgebieten, die nun außerhalb der neuen Landesgrenzen lagen, wirken konnten. Die neugeschaffenen staatlichen sowie die auf Selbstverwaltung basierenden von der Gesellschaft getragenen kulturel- 
len Institutionen und Organisationen trugen maßgeblich dazu bei, die geistige Einheit des historischen Ungarns und die mit dieser einhergehende großungarische Identität zu bewahren und weiter zu stärken.

$\mathrm{Zu}$ diesen neu geschaffenen, staatlichen Institutionen gehörten auch die ersten staatlichen Literaturpreise des unabhängigen Königreichs Ungarn, die den Ausgangspunkt für das moderne Literaturpreissystem des Landes bilden sollten: die Magyar Corvin Lánc (Ungarische Corvin Kette) sowie der Magyar Corvin Koszorú (Ungarische Corvin Kranz). Als Reichsverweser des Königreichs Ungarn verfügte Miklós Horthy im Vergleich zu den früheren königlichen Befugnissen zwar nur über eingeschränkte, eher einem modernen Staatschef entsprechende Befugnisse, doch während ihm beispielsweise die Verleihung von Adelstiteln rechtlich nicht möglich war, lag die Gründung von neuen Orden und Auszeichnungen sowie deren Vergabe sehr wohl in seiner Macht. Diese Möglichkeit stellte für Horthy anfangs eine taktische Herausforderung dar: Während die militärische Führungsriege im März 1920 noch der Meinung war, dass Horthy keine neuen Auszeichnungen oder Verdienstorden ins Leben rufen solle, da seine Regierungszeit ja nur eine vorübergehende war, wurde die Notwendigkeit von Auszeichnungen aus innen- und außenpolitischen Gründen immer deutlicher. ${ }^{11}$ Das durch den Friedensvertrag von Trianon territorial geschrumpfte und wirtschaftlich geschwächte Ungarn konnte es sich nicht leisten, auf die mit den Auszeichnungen verbundene Geste der Ehrung all jener, die sich ihm in der dem Krieg folgenden Krisenzeit als politische Unterstützer im Ausland oder tatkräftige Hilfskräfte im Inland erwiesen, zu verzichten. Mit dem Zusammenbruch der Habsburgermonarchie war aber auch das ehemals in der Monarchie etablierte und mit deren Symbolen verknüpfte Auszeichnungssystem Ungarns für das neue Königreich Ungarn unbrauchbar geworden. Die ungarische Führung stand also vor der Aufgabe beziehungsweise vor der lang ersehnten Möglichkeit, das erste unabhängige, moderne ungarische Auszeichnungssystem ins Leben zu rufen. Den Anfang machten Auszeichnungen, die militärische, humanitäre und zivile Leistungen honorieren sollten und gleichermaßen an Ungarn sowie Nicht-Ungarn vergeben werden konnten: 1920 erfolgte die Gründung der Vitézi Szervezet (Institution der Husaren), 1922 wurde die Magyar Vöröskereszt Díszjelvénye (Ehrennadel des Ungarischen Roten Kreuzes) ins Leben gerufen und 1923 wurden die Satzung des Magyar Érdemkereszt (des Ungarischen Verdienstkreuzes) sowie der Magyar Érdemérem (der Ungarischen Verdienstmedaille), die bereits seit 1921 basierend auf den Vorstellungen von Graf István Bethlen in Planung waren, offiziell abgesegnet. ${ }^{12}$

Obgleich das bis 1930 etablierte System an Auszeichnungen bereits relativ differenziert war, zeigte sich in einigen spezialisierten Betätigungsfeldern ein noch nicht abgedecktes Bedürfnis nach adäquaten Ehrungen und Auszeichnungsmöglichkeiten. Folglich rief der Reichsverweser Horthy am 11. Oktober 1930 die 
Corvin-Preise, also die Magyar Corvin Lánc (Ungarische Corvin Kette) sowie den Magyar Corvin Koszorú (Ungarischen Corvin Kranz), ins Leben, die als hohe staatliche Auszeichnungen für herausragende Betätigungen im Sinne der Beförderung der Entwicklungen auf den Gebieten der Wissenschaft, der Bildung, der Kunst sowie der Literatur fungieren sollten. ${ }^{13}$ Den grundlegenden Anstoß dazu gab der amtierende Religions- und Bildungsminister Klebelsberg. Seiner Überzeugung nach sollte die über die neuen Grenzen Ungarns hinaus sichtbare und wirksame Versicherung der kulturellen Überlegenheit Ungarns durch die Pflege der ruhmreichen Vergangenheit sowie der publikumswirksamen und beständigen Bestätigung der heimischen intellektuellen Elite erfolgen. Die Gründung der Corvin-Preise fügte sich folglich organisch in das Programm der ,nationalen Wiedergeburt" ein.

\begin{abstract}
,[M]eg akarunk emlékezni azokról is, kik a mai páratlanul nehéz időkben a magyar müvelődés szintjének fenntartásáért és emeléséért folyó szellemi munkából kimagasló tehetséggel és rendkívüli odaadással veszik ki részüket [...] Ezen férfiak külön elismerésben részesüljenek: a nagy mecénás királynak, Hunyadi Mátyásnak emlékére 12 Corvin láncot és 60 Corvin-koszorút alapítok. “14
\end{abstract}

Am 24. Februar 1931 erfolgte die erste Vergabe der Corvin-Preise, die insgesamt 72 Preisträger wurden bereits zwei Wochen nach der offiziellen Gründung des Preises, am 25. Oktober 1930, im Budapesti Közlöny (Budapester Amtsblatt) bekanntgegeben.

Bekannt ist allerdings, dass bereits bei der ersten Runde der Preisvergabe ein Verstoß gegen die Statuten der Corvin-Preise stattgefunden hatte. Einer der ersten Preisträger der Corvin Kette war der Kulturminister Kuno von Klebelsberg selbst. Der Preis wurde ihm für seine Verdienste im Rahmen seiner Bildungsoffensive zugesprochen. Den Statuten des Preises entsprechend hätte der Kulturminister sich den Preis quasi selbst mit seiner Unterschrift zusprechen müssen. Folglich ließ man den betreffenden Antrag, der Klebelsbergs Nominierung enthielt, von seinem Vorgesetzten, dem Ministerpräsidenten István Bethlen, unterschreiben. Das eigentlich moralische Problem wurde als ein rechtliches getarnt und dementsprechend behandelt. ${ }^{15}$

Interessant ist ebenso, dass in der Gründungsurkunde, wie im obigen Zitat ersichtlich, lediglich von auszuzeichnenden Männern die Rede ist. Tatsächlich aber wurden bereits 1931 im Rahmen der ersten Preisvergabe vier Frauen ausgezeichnet - darunter die Schriftstellerin Cecil Tormay. ${ }^{16}$

Murányi weist darauf hin, dass es Klebelsbergs primäre Absicht war, mit der Gründung der Corvin Kette und des Corvin Kranzes eine Art Klub der intellektuellen Elite ins Leben zu rufen. Die Statuten der Corvin Kette und des Corvin Kranzes entsprachen dieser Grundidee Klebelsbergs: Der Preis wurde für herausra- 
gende Leistungen innerhalb der Gebiete der Wissenschaft, des Bildungswesens, der Kunst sowie der Literatur zuerkannt und vom Reichsverweser Horthy im Rahmen einer feierlichen Zeremonie übergeben. Die Anzahl der insgesamt zu vergebenden Auszeichnungen war beschränkt: Es durften maximal 12 Personen gleichzeitig Träger der Corvin Kette und maximal 60 Personen gleichzeitig Träger des Corvin Kranzes sein. Zusammen bildeten sie den sogenannten Corvin-Orden. In diesen geschlossenen, elitären Kreis konnte nur dann ein neues Mitglied aufgenommen werden, wenn einer der insgesamt 72 Preisträger starb. In diesem Fall wurde die Auszeichnung an das Kabinett des Reichsverwesers zurückgeschickt und eine andere Person konnte mit dem Preis ausgezeichnet werden. Die Entscheidung, wer die Auszeichnung bekommen sollte, lag den Statuten entsprechend in letzter Konsequenz beim jeweiligen Religions- und Unterrichtsminister, der auch für kulturelle Angelegenheiten verantwortlich war. Dieser musste jeden einzelnen Kandidaten mit seiner Unterschrift bestätigen. Die eigentliche Auswahl der Auszuzeichnenden erfolgte jedoch durch die Träger der Corvin-Preise, also die Mitglieder des Corvin-Ordens. So fungierten die Preisträger als autonomes Gremium, das in einer geheimen Abstimmung eine Liste von Kandidaten aufstellte, die nach Freiwerden eines Platzes innerhalb des Ordens durch die Verleihung einer Corvin Kette oder eines Corvin Kranzes in diesen aufgenommen werden sollten. ${ }^{17}$ Details über die Hintergründe der Entscheidungsfindung seitens des Gremiums und der Zustimmung oder Ablehnung seitens des Ministers sind nicht bekannt. Das Vallás- és Közoktatásügyi Minisztérium (Ministerium für Religion und Bildung) existierte vom 10. März 1867 bis zum 19. Mai 1951 und das Ungarische Nationalarchiv beherbergt heute einen Teil jener Dokumente, die zwischen den Jahren 1867 und 1945 entstanden waren. Doch der Großteil der Unterlagen des Ministeriums fiel den Archivbränden in den Jahren 1944/45 und 1956 zum Opfer. Folglich wurden die präsidialen Schriften bezüglich kirchlicher, stifterischer, künstlerischer und wissenschaftlicher Angelegenheiten sowie rund um Fragen der Leibeserziehung, der Schulbuchherausgabe und der außerschulischen Volksbildung zur Gänze oder größtenteils vernichtet. ${ }^{18}$ Ein wichtiges Detail in Zusammenhang mit der Corvin Kette und dem Corvin Kranz ist, dass die Auszeichnung mit keinerlei Preisgeld verbunden war. Es handelte sich also um rein symbolisches Kapital, das mit den Corvin-Preisen verbunden war.

\section{Preisträger der Corvin Kette}

Die Corvin Kette wurde in den Jahren 1930, 1935, 1937, 1938, 1939, 1940, 1941 und 1942 vergeben. Im ersten Vergabejahr wurde der prestigeträchtige Preis an drei Kulturpolitiker vergeben: Graf Kuno Klebelsberg, Albert Berzeviczy und 
Baron Gyula Wlassics. ${ }^{19}$ Wlassics bekleidete von 1895 bis 1903 das Amt des Ministers für Religion und Bildung unter den Ministerpräsidenten Dezső Bánffy (1895-1899) und Kálmán Széll (1899-1903) und machte sich in erster Linie aufgrund der von ihm durchgesetzten bürgerlichen Reformen einen Namen, die beispielsweise Frauen das Universitätsstudium an der geisteswissenschaftlichen, der medizinischen und der pharmazeutischen Fakultät ermöglichten oder die Gründung der Akademie der Bildenden Künste in die Wege leiteten. ${ }^{20}$ Berzeviczy war Wlassics‘ Nachfolger und von 1903 bis 1905 während des Kabinetts von István Tisza im Amt. Berzeviczy, der als treuer Anhänger des Ausgleichs von 1867 galt und ein Vertreter der kirchenpolitischen Gesetze war, war nach seiner Tätigkeit als Minister von 1905 bis 1936 der Präsident der Ungarischen Akademie der Wissenschaften. ${ }^{21}$

Unter den insgesamt 23 Trägern der Corvin Kette befinden sich lediglich zwei Schriftsteller: Ferenc Herczeg und Sándor Reményik. Ersterer erhielt die Corvin Kette ebenfalls bereits im Jahr 1930 im Rahmen der ersten feierlichen Verleihung der neuen Auszeichnung, letzterer erhielt sie zehn Jahre später im Jahr 1940. Im Folgenden soll genauer auf die beiden Preisträger eingegangen werden.

Das kulturelle Leben in der Zwischenkriegszeit war anfangs weiterhin mehrschichtig und produktiv - die meisten wichtigen intellektuellen Tendenzen und maßgeblichen Zeitschriften der Jahrhundertwende hatten sowohl den Weltkrieg als auch die politisch-ideologisch wechselhafte Zeit bis 1920 überdauert. Die noch vor dem Weltkrieg etablierten und bis in die 1930er Jahre in der Form bestehenden literarisch-ideologischen Lager und deren ebenso bereits etablierten Persönlichkeiten standen sich nach wie vor gegenüber, ergänzt wurde das Feld durch das Aufkommen der so genannten népi írók (Volkstümlichen Schriftsteller) ${ }^{22}$, doch eine herausragende Stellung nahm in der Horthy- ̈̈ra doch der literarische Konservatismus ein. So entsprach er mit seinen traditionsverliebten, chauvinistischen Momenten sowie seinem anti-urbanen, der alten Ordnung verpflichteten Ton nicht nur der christlich-patriotischen und revisionistischen Stimmung, die sich ab Anfang der 1920er Jahre in Ungarn ausbreitete, sondern komplementierte auch ideal die von Klebelsberg und Hóman verfolgten kulturpolitischen Konzepte auf der künstlerisch-literarischen Ebene, was sich auch in der aktiven, staatlichen Unterstützung der diese literarische Richtung vertretenden Schriftsteller bemerkbar machte. ${ }^{23}$ Ihr ungekrönter König war einer der beiden Literaten, die mit der Corvin Kette ausgezeichnet wurden, nämlich Ferenc Herczeg. Der in der Horthy-Ära ausgesprochen populäre Autor war Chefredakteur der konservativen, nationalistisch eingestellten, ab 1894 und bis 1949 wöchentlich erscheinenden Literaturzeitschrift Új Idők (Neue Zeiten), die während der Zwischenkriegszeit mit ca. 30.000 Abonnenten mitunter mehr regelmäßige Abnehmer hatte als alle anderen Zeitschriften zusammengenommen. ${ }^{24} \mathrm{Im}$ Vorwort an die Leserschaft beschwört Herczeg in seiner Zeitschrift, die für die älteren Werte einstand, neue 
Zeiten herauf, die innerhalb der ungarischen Familie eingekehrt seien und denen die Zeitschrift Rechnung tragen wolle. Beide, sowohl die ungarische Familie als auch die Zeitschrift, könnten mit diesen neuen Zeiten nur dann adäquat umgehen,

\begin{abstract}
„[...] ha a régi időkből [Hervorhebung im Orig.] öröklött nemzeti tőkéjét, faji sajátosságait, hagyományait, hajlamait és tehetségeit teljesen beleilleszti az új idők modern keretébe, és alapjává teszi a speciális magyar műveltségnek. Az igazi, az élő irodalom és müvészet részint vezeti, részint követi ezt az átalakulást. Mi, mint újság, ezt az irodalmat és ezt a müvészetet akarjuk ápolni és olvasóinkkal megismertetni, olyan formában, hogy ne jusson eszébe senkinek irigyelni azokat a külföldi irodalmakat, amelyek egy régi, megállapodott - és nekünk idegen világ életével foglalkoznak."
\end{abstract}

Anfangs umging die Zeitschrift politische Streitfragen und bediente den konservativen Geschmack der ungarischen, christlichen Mittel- und Beamtenschicht, was sie zum meistgelesenen Familien- und Literaturmagazin des Landes aufsteigen ließ.

Herczeg selbst veröffentlichte laufend romantisierende historische Dramen und Romane sowie moralisierende Geschichten über die dekadente, moderne Gesellschaft. 1925 erschien anlässlich des 40-jährigen Jubiläums des Beginns seiner literarischen Karriere eine 40 Bände umfassende Gesamtausgabe seines Werkes, seine Dramen wurden im Nationaltheater gespielt und 1925 wurde er von der Ungarischen Akademie der Wissenschaft für den Nobelpreis nominiert. ${ }^{25}$ Herczeg wurde 1929 außerdem zum Präsidenten der Magyar Reviziós Liga (Ungarischen Revisionistischen Liga) gewählt, die es sich zur Aufgabe gemacht hatte, die irredentistischen Bestrebungen in Ungarn und im Ausland zu bündeln und gezielte Aktionen zu organisieren, um die Aufmerksamkeit der übrigen Weltnationen auf die Ungerechtigkeit des Friedensvertrages von Trianon zu lenken. Der Autor war für diese Position in mehrfacher Hinsicht geeignet: Er selbst stammte aus dem Banat, einer nach dem Ersten Weltkrieg von Ungarn weggefallenen Provinz, und er hatte sein politisches Engagement um die Jahrhundertwende als Abgeordneter im Parlament unter Beweis gestellt, was ihm eine abermalige Berufung zum Mitglied des Oberhauses beschert hatte. Wichtiger jedoch war die Tatsache, dass er als renommierter Schriftsteller der Vorstand mehrerer Flüchtlingsverbände war und dutzende Artikel und Veröffentlichungen mit revisionistischem Inhalt veröffentlicht hatte. ${ }^{26}$

Sándor Reményik war ein ungarischer Schriftsteller aus Kolozsvár (Klausenburg), das nach dem Friedensvertrag von Trianon zu Rumänien gehörte. Der Autor war für seine folkloristische Lyrik bekannt geworden, für die er auch zweimal mit dem Baumgarten Preis ausgezeichnet worden war, nämlich bereits 1937 und 1941, ein Jahr nach der Verleihung der Corvin Kette. Reményik galt als Vertre- 
ter des sogenannten Transsylvanismus ${ }^{27}$. Außerdem war er zuerst der Chefredakteur, später einer der Hauptmitarbeiter der siebenbürgischen Literaturzeitschrift Pásztortüz (Hirtenfeuer). ${ }^{28}$ Anlässlich des zehnjährigen Jubiläums der Gründung der Corvin-Preise wurde die Anzahl der zu vergebenden Preise im Oktober 1940 in Hinblick auf die zur „Heiligen Ungarischen Krone zurückgekehrten siebenbürgischen und östlichen Landesgebiete ${ }^{\text {"229 }}$ erhöht: jene der Corvin Kette um drei, jene des Corvin Kranzes um zwanzig. Es überrascht daher nicht, dass 1940 ausgerechnet ein siebenbürgischer Schriftsteller die Corvin Kette überreicht bekommen hat.

\section{Preisträger des Corvin Kranzes}

Der Corvin Kranz wurde zwischen 1930 und 1943 an insgesamt 113 Personen vergeben, dabei waren 19 von ihnen Schriftsteller oder Dichter. Auffallend ist, dass 11 der 19 Schriftsteller, die mit dem Corvin Kranz ausgezeichnet wurden, entweder in Siebenbürgen beheimatet waren oder zumindest ursprünglich aus Siebenbürgen oder Oberungarn stammten und erst im Laufe ihrer Hochschulstudien oder beruflichen Laufbahnen nach Budapest übersiedelten. Zusätzlich sticht auch die Zahl der Frauen hervor: Drei von den insgesamt 19 mit dem Corvin Kranz ausgezeichneten Literaten waren weiblich, nämlich Cecil Tormay (1930), Irén Gulácsy (1939) und Mária Berde (1940). Von diesen dreien stammten wiederum zwei aus Siebenbürgen. Alle drei Frauen vertraten im Grunde ähnliche, der in der Zwischenkriegszeit herrschenden Elite entsprechende, politische Weltanschauungen, allerdings unterschiedlich stark ausgeprägt. Wenn auch die Auszeichnung von Gulácsy und Berde mit deren Verwurzelung in Siebenbürgen dem kulturpolitischen Ziel der Pflege des Kontaktes mit den nunmehr im benachbarten Ausland lebenden Ungarn entsprach, war doch ebenso aus kulturpolitischer Perspektive Cecil Tormay zweifellos die bedeutendste Figur unter den drei Frauen, zumal sie neben Herczeg die zweite führende Persönlichkeit der nationalkonservativen Literaten war und mit ihrem zweibändigen Bujdosó könyv (Buch aus dem Versteck, 1921) zu ähnlicher Berühmtheit gelangt war. Tormay $^{30}$ stammte aus der Klasse der ungarischen Großgrundbesitzer, ihr Vater war Ministeriumsbeamter. Nach dessen Tod erhielt die damals 31-jährige, beschäftigungslose Tormay aufgrund ihrer Verbindungen den Titel der Stiftsdame, der ihr ein regelmäßiges Einkommen sowie den gesellschaftlichen Rang einer Dame einbrachte - beides ausgesprochen wichtige Faktoren für die zeitlebens unverheiratete Schriftstellerin, die sich ihre Existenz stets selbst sichern musste und dies allein durch ihr Schreiben tun wollte. Doch neben der Schriftstellerei hatte Tormay nach dem Zusammenbruch der Räterepublik auch politische Ambitionen - bis zu ihrem Tod nahm sie aktiv in der Politik auf der Seite der Restauration, der Elite der Großgrundbesitzer sowie des christlich-nationalen Kleinadels teil. 
Sie wurde zum Beispiel der nun wahlberechtigten Frauen hochstilisiert und war auch bereit, als solches ihre schriftstellerische Tätigkeit ihrer politischen Rolle unterzuordnen. Tormay begann schon in jungen Jahren zu schreiben, ihre ersten Erzählbände erschienen bereits zur Jahrhundertwende. Ihren ersten Erfolg erzielte sie mit dem autobiographische Züge aufweisenden, 1914 erschienenen Roman A régi ház (Das alte Haus), ihr bedeutendstes und zugleich erfolgreichstes Werk stellt allerdings das 1920-21 erschienene, zweibändige, als Tagebuch ${ }^{31}$ verfasste Bujdosó könyv (Buch aus dem Versteck) dar. Das Buch, in dem die Tagebuchschreiberin die Kriegspolitik der herrschenden Klassen in Ungarn verteidigt und die ungarischen Juden für die Niederlage verantwortlich macht, ließ Tormay zur von der gesellschaftlichen und politischen Elite der Zwischenkriegszeit gefeierten Autorin und Ideologin aufsteigen. Bereits 1919 war sie an der Gründung des Magyar Asszonyok Nemzeti Szövetsége (MANSZ - Nationalen Verbandes Ungarischer Frauen $)^{32}$ beteiligt und wurde dessen Präsidentin. Ziel des Verbandes war die Unterstützung der Politiker der christlich-nationalen Parteien bei den Wahlen sowie das Zurückdrängen der linksgerichteten Presse durch die 1921 ins Leben gerufene Monatszeitschrift des MANSZ mit dem Titel A Magyar Asszo$n y$ (Die ungarische Dame), die für Tormay ebenfalls zum wichtigen Organ zur Verbreitung ihrer politischen Auffassungen wurde. 1923 machte der Religionsund Bildungsminister Kuno Klebelsberg die Schriftstellerin zur Chefredakteurin der von ihm ins Leben gerufenen Zeitschrift Napkelet (Morgenland/Orient), die zu einem weiteren Medium für Tormays irredentistische Ansichten und ihren mal offen, mal versteckt zutage tretenden Antisemitismus wurde und ihren in der Zwischenkriegszeit aufgebauten Kultstatus weiter befeuerte. Die Zeitschrift, die sich als Gegenprogramm zur Zeitschrift Nyugat (Westen) verstand, konnte dank des Mitherausgebers János Horváth, der mit seinen politisch-ideologischen Überzeugungen zwar der Blattlinie entsprach, darüber hinaus allerdings auch ein beachtenswerter Literaturkritiker war, neben den politisierenden Beiträgen auch Schriften angesehener, nicht nationalkonservativer Autoren wie etwa Géza Gárdonyi, Gyula Szekfü oder Dezső Szabó publizieren. Trotzdem war ihr literarisches Niveau nicht mit jenem von Nyugat vergleichbar - zu sehr war die Ära und dementsprechend auch der überwiegende Teil der Beiträge in Tormays Zeitschrift geprägt vom immer stärker werdenden Chauvinismus, Rassismus und anachronistischen Konservatismus, der mit dem die Politik der Zwischenkriegszeit bestimmenden Irredentismus einherging. ${ }^{33}$ Die Auszeichnung mit dem Corvin Kranz im Jahr 1930 war für Tormay, die zur emblematischen Schriftstellerin der Horthy-Ära und zur Präsidentin der größten Frauenorganisation des Landes aufgestiegen war, die Krönung ihres Ruhmes und zeugte von ihren exzellenten Verbindungen zur herrschenden Elite. ${ }^{34}$

Irén Gulácsy ${ }^{35}$ war eine erfolgreiche Romanschriftstellerin, die den Großteil ihrer Lebenszeit in Nagyvárad (Oradea / Großwardein) sowie in Budapest 
verbracht hatte, wo sie bei einem Luftangriff während des Zweiten Weltkrieges umkam. Ihre schriftstellerische Karriere begann Gulácsy in Nagyvárad - sie war ab 1919 Mitarbeiterin der Tageszeitung Nagyvárad und publizierte Artikel in den Zeitschriften Pásztortüz (Hirtenfeuer), Genius, Brassói Lapok (Kronstädter Blätter), Keleti Újság (Östliche Zeitung), Ellenzék (Gegner), der unter der Chefredaktion von Tormay stehenden Napkelet und Magyar Kisebbség (Ungarische Minderheit). Ihr erster Roman Zord Idö (Rauhe Zeit) erschien 1925, sie veröffentlichte laufend Novellen und Dramen, aber ihr wichtigstes Werk stellt ihr 1927 mit einem Aufsatz von László Németh erschienener, historischer Roman Fekete vőlegények (Schwarze Bräutigame) dar. Nach ihrer Übersiedlung nach Budapest veröffentlichte sie weitere historische Romane, die zu großen Publikumserfolgen wurden. Daneben war sie Mitarbeiterin der Zeitschriften Magyarság (Ungartum), Pesti Hirlap (Pester Nachrichtenblatt) und Herczegs Új Idők.

Die 1889 in eine siebenbürgische, intellektuelle Familie hineingeborene Mária Berde war als Schriftstellerin, Journalistin und Übersetzerin bekannt geworden. Ihr erstes Gedicht veröffentlichte sie bereits während ihrer Studienzeit 1906 in der Zeitschrift Pesti Napló (Pester Tagebuch), sechs Jahre später folgte die Veröffentlichung ihres ersten Gedichtbandes. Berde war eine hochgebildete, mehrerer Sprachen mächtige Frau, deren schriftstellerische Laufbahn mehrere Phasen aufweist. So entwickelte sie sich im Laufe ihres Lebens nicht nur von der Lyrikerin zur Prosaautorin, sondern auch zu einer sehr aktiven und führenden Figur des ungarischsprachigen Literaturbetriebs in Siebenbürgen und engagierte sich im Sinne der Koexistenz und veranstaltete Vortragsreihen zur Vermittlung der rumänischen Literatur. ${ }^{36}$

Ihre schriftstellerischen Anfänge waren noch stark von ihrer weiblichen, ja feministischen Sichtweise geprägt. Tatsächlich sind immer wiederkehrende Themen in ihrem Werk die sich selbst befreiende oder sich selbst befreien wollende Frau, deren gesellschaftliche Position und moralische Situation, die Frage der Partnerwahl und die Gefühlswelt der Frauen. Erwähnenswert ist in diesem Zusammenhang ihr 1925 erschienener Roman A Szent Szégyen (Die Heilige Scham), mit dem sie sich den herrschenden gesellschaftlichen Vorurteilen entgegenstellt und die Geschichte einer jungen Frau erzählt, die ein uneheliches Kind zur Welt bringt und es in weiterer Folge alleine großzieht. Sie beweist in diesem Roman, dass Frauen nur dann ihre Freiheit erringen können, wenn sie durch selbständige Landarbeit ihre finanzielle Unabhängigkeit sichern können. ${ }^{37}$ In den 1920er Jahren jedoch wandte sich ihr Interesse auch den gesellschaftlichen Fragen ihrer Zeit zu. Dabei zeichnen sich ihre Arbeiten durch einen nüchternen, kultivierten Stil aus: In ihrem Roman Földindulás (Landbewegung), den sie bereits 1924 verfasst hatte und der erst 1931 erschien, zeichnet sie den Untergang des siebenbürgischen Kleinadels nach dem Krieg nach, wobei sie als Rettung vor dem Abrutschen zur Annäherung an das Volk sowie die Verständigung mit dem rumänischen Bürgertum und der rumänischen intellektuellen Elite rät. 
Vertrat Berde in ihren Werken zwar für ihre Zeit durchaus revolutionär anmutende Meinungen in Bezug auf die Position der Frauen in der Gesellschaft, ihrer Gleichwertigkeit Männern gegenüber sowie ihr Streben nach Freiheit und Selbstbestimmtheit, so propagierte sie in ihnen keine politischen Extreme. Der siebenbürgische Schriftsteller István Katona Szabó erinnert sich 1957 an sie wie folgt:

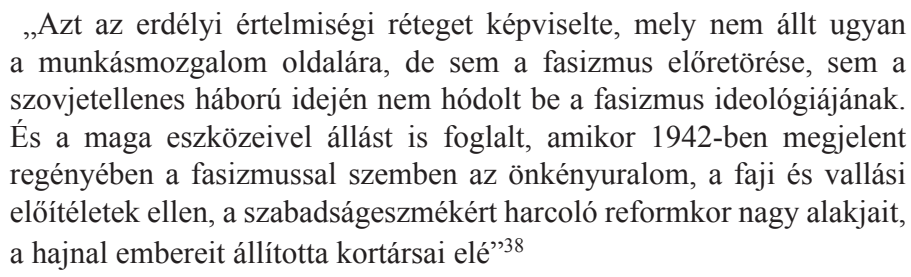

Den Corvin Kranz bekam Berde 1940 verliehen, zwei Jahre vor dem Erscheinen ihres Romans A hajnal emberei (Die Menschen der Morgendämmerung), mit dem sie den Helden der siebenbürgischen Reformbewegung wie etwa Károly Szász und Miklós Wesselényi ein literarisches Denkmal setzen wollte und für den sie mit dem Baumgarten-Preis ausgezeichnet wurde.

Der in der Horthy-Ära und insbesondere während der Amtszeit von Klebelsberg als Kulturminister stattgefundene Schulterschluss der Politik mit der Literatur, also die erste, dezidierte, einer gewissen Systematik und kulturpolitischen Strategie folgende Hinwendung des Staates zur Literatur, genauer zu ausgewählten Vertretern einer bestimmten literarischen Strömung erklärt sich auch mit der steigenden Bedeutung der Literatur in der Gesellschaft. Im Gegensatz zur Zeit vor dem Ersten Weltkrieg gewann die Literatur in der Horthy-Ära deutlich an Geltung, ihre Verbreitung erreichte neue Dimensionen - das Interesse für Literatur stieg auch innerhalb des Kleinbürgertums und der gebildeten Arbeiterschaft, entsprechend wuchs auch der Buchmarkt. ${ }^{39}$ Dies führte zu einem grundsätzlichen Anwachsen der Publikationszahlen von 2.378 Titel in 1913, beziehungsweise 2.318 Titel in 1921, auf 3.403 Titel im Jahr 1930 und schließlich 3.920 Titel im Jahr 1934. 1941 wurden bereits mehr als 5.000 Bücher publiziert. Im Jahr 1932 verzeichnete der Buchmarkt einen deutlichen Rückschlag aufgrund der wirtschaftlichen Depression - die Zahl der Buchpublikationen belief sich auf nur 2.842 Titel. Ungefähr ein Viertel der publizierten Bücher waren der Belletristik zuzuordnen, später verschob sich das Verhältnis auf rund ein Drittel belletristischer Bücher. Von diesem Anteil war circa die Hälfte Schöne Literatur, die andere Hälfte Trivialliteratur. Betrachtet man die Auflagenzahlen, zeigt sich ein wesentlich schlechteres Verhältnis: 1938 bestand die Gesamtauflagenzahl von 7 Millionen Exemplaren aus 4,8 Millionen Abenteuer-, Detektiv- und Liebesromanen, die zu günstigen Preisen in Form von Romanheften zu kaufen waren, und 
nur 2,2 Millionen Exemplare schöngeistiger Literatur. Die Trivialliteratur nahm also 70 Prozent der Belletristik ein. Die Auflagenzahlen der Schönen Literatur waren demnach weit geringer. Gedichtbände zeitgenössischer Autoren wurden üblicherweise in einer Auflage von rund 500 Stück gedruckt, Romane in einer Auflage von 2-3.000 Stück. Die Werke renommierter, berühmter Autoren bildeten einzelne Ausnahmen, so wie etwa die Ausgabe der gesammelten Gedichte von Mihály Babits ein Jahr nach dessen Tod im Jahr 1941 eine Auflage von 12.000 Stück erlebte oder auch einzelne Werke von Endre Ady es gegen Ende der Zwischenkriegszeit zu Auflagen von 15-20.000 brachten. ${ }^{40}$

\section{Fazit}

Die ursprünglich von Miklós Horthy gegründeten und von Viktor Orbán wieder eingeführten Corvin-Preise stellten in der Zwischenkriegszeit eine stark von der jeweils aktuellen politischen Richtung beeinflusste, direkte kulturpolitische Maßnahme zur publikumswirksamen, öffentlichen Bekräftigung und Beförderung des (kultur)politischen Konzepts sowie zur Schaffung einer der aktuellen politischen Stimmung entsprechenden intellektuellen Elite dar. Dem damaligen Zeitgeist entsprechend war diese nicht frei von nationalistisch-irredentistischen und antisemitischen Auffassungen, die bei heutiger Betrachtung kritisch hinterfragt und entsprechend kontextualisiert werden müssen. Insbesondere bei der Vergabe eines gleichnamigen Preises ist ein solches Vorgehen, also speziell die differenzierte Betrachtung des historischen Hintergrundes, unumgänglich.

\section{Notes}

1 Siehe die Verfügung 2/2001.(VIII. 14.)ME

2 Siehe dazu: http://corvinlanc.kormany.hu/corvin-lanc-2001- (18.10.2016)

3 Ibid.

4 Der Inhalt des Artikels stammt zum größten Teil aus der Dissertation der Verfasserin, die unter dem Titel „Ausgezeichnete Literatur. Die Kulturpolitik Ungarns im kurzen 20. Jahrhundert am Beispiel des staatlichen Literaturpreissystems“ im Herbst 2016 an der Universität Wien eingereicht worden ist.

5 Noch bevor Bálint Hóman als Kulturpolitiker tätig wurde, publizierte er bereits 1920 einen Artikel, in dem er für die Steigerung der staatlichen Mittel für den Wissenschafts- und Bildungsbereich plädiert, um Ungarn auf dem Gebiet der Wissenschaft und Forschung auf das Niveau der westeuropäischen Staaten zu heben und konkurrenzfähig zu machen, das Ansehen des Landes wiederherzustellen. Siehe: Hóman, Bálint: A magyar tudományosság jövője. In: Budapesti Szemle. 181 (1920), S. 127-161

6 „Ich möchte im allgemeinen Bewusstsein verankern, dass im in Folge des Friedens von Trianon abgerüsteten Ungarn das Kultusministerium eigentlich auch das Verteidigungsministerium ist. In dem Sinne ist es ein Verteidigungsministerium, als man jetzt in erster Linie mit den Waffen des Geistes, der Bildung unsere Heimat verteidigen muss, und mit diesen Mitteln müssen wir 
den Nationen der Welt immer und immer aufs Neue beweisen, dass der Ungar in seinem zweitausendsten Jahr seines wechselvollen Lebens noch lebensfähig und stark ist, und dass es eine große historische Ungerechtigkeit ist, ihn zu verletzen.“- Klebelsberg, Kuno: A kultusztárca programja. A vallás- és közoktatásügyi tárca kötségvetése alkalmából 1926. február 20-án tartott beszéd. Zitiert nach: Kiss 1999, S. 239

7 „In der Schule habt ihr schon gelernt, dass sich das Gebiet von Groß-Ungarn über 325.000 Quadratkilometer erstreckt hat. Das Ungarn nach Trianon hat nur 92.000 Quadratkilometer. Ihr wisst auch, dass in Groß-Ungarn 21 Millionen Menschen gelebt haben, im Gegensatz dazu hat das Ungarn nach Trianon nur 8 Millionen Einwohner. Unsere Heimat ist beinahe auf ein Drittel zusammengeschrumpft. Wenn wir all dem zum Trotz nicht im Laufe der Nationen das Gebiet verlieren wollen, das das Ungartum früher besetzt hatte, dann muss das Ergebnis unserer Arbeit mindestens genauso groß sein, wie jenes der 21 Millionen Einwohner des historischen Ungarns früher. Aber wir müssen auch den inneren Wert unserer Nation steigern, wir müssen nicht nur die Leistung der einzelnen Menschen jeder für sich, sondern die Ergebnisse der Zusammenarbeit der ganzen Nation steigern." - Kunó Klebelsbergs Radiorede an die ungarische Jugend, 1924 (Ausschnitt) - zitiert nach: Szakály, István; Gitta Sódar: A kultuszminiszter. Klebesberg Kunó, a kimondhatatlan nevü gróf. In: Hitel, 24/7 (2011), S. 3-21, hier S. 3

8 „Wir müssen arbeiten und vergessen wir nicht, dass die ungarische Heimat heute nicht in erster Linie vom Schwert, sondern von der Kultur erhalten und wieder groß gemacht werden kann.“ - Klebelsberg, Kuno: Beszédei, Cikkei és Törvényjavaslatai 1916-1926. Budapest 1927, S. 604-608., S.604

9 Vgl. Drabancz, Róbert M.: Egy európai magyar kultúrpolitikus. Gondolatok Klebelsberg Kunóról. In: Új pedagógiai szemle, 50/7-8 (2000), S. 195-199, hier: S. 197

10 „In dieser Zeit wurde die kulturelle Erneuerung zu einem politischen Programm, das seinen Sinn in der Stärkung und Neugestaltung des nationalen Gefühls und in der Annäherung an die europäischen Werte gefunden hatte. Bestimmende Elemente der von Ministerpräsident István Bethlen identischen politischen Überzeugungen waren der Schutz des bis zum Ende des 19. Jarhunderts entstandenen, liberalen staatlichen Insitutionensystems sowie die Bewahrung des Vorzugs der wohlhabenden und gebildeten gesellschaftlichen Schichten, in erster Linie der Aristokratie und der besitzenden Adligen. Beide [Klebelsberg und Bethlen, Anm. EE] dachten an einen autoritären, starken Staat.“- Drabancz 2000, S. 196

11 Dies galt umso mehr, als der am 21. März 1919 zustande gekommene revolutionäre Regierungsrat der ungarischen Räterepublik die Vergabe sämtlicher bis dahin existenter Auszeichnungen einstellte. Die Begründung dafür findet sich in einer Verfügung des Rates: „A magyarországi Tanácsköztársaságban nincs nemesség, rang és cím, nincsenek rendjelek, érdemrendek és más hasonló kitüntetések." (In der ungarischen Räterepublik gibt es keinen Adel, keinen Rang und Titel, keine Orden, keine Großkreuze und andere ähnliche Auszeichnungen.) - zitiert nach Gyurákovics, Norbert: Az érdem elismeréséül...In: Somogyi Múzeumok Közleményei. 15, 2002. S. 257-274, hier S. 261

12 Vgl. Makai / Héri 2002, S.35ff

13 Vgl. ibid., S.38

14 Zitiert nach: Murányi, Gábor: Rend a lelke. A Corvin-lánc históriája. In: Múlt-kór. Negyedéves történelmi magazin. 2 (2012), S. 12

15 Vgl. Murányi 2012, S.13

16 Weiters wurden die Opernsängerin Erzsébet Sándor sowie die Schauspielerinnen Emilia Márkus und Gizi Bajor ausgezeichnet. Vgl. Murányi Múlt-kor, S.13

17 Murányi, Gábor: A Corvin lánc története. In: HVG, 13. November 1999. S. 97-104, hier S. 99

18 http://mnl.gov.hu/bal_menusor/hasznalat/kutatas/iratanyag_leirasa/polgari_kori_kormanyhatosagok_leveltarai.html\#7 (16.10.2014) 
191935 wurde auch Hóman Bálint mit der Corvin-Kette ausgezeichnet, allerdings zu diesem Zeitpunkt noch aufgrund seiner Verdienste als Historiker. 1932 übernahm Hóman von Klebelsberg das Amt des Kulturministers.

20 Vgl. Magyar Életrajzi Lexikon http://mek.niif.hu/00300/00355/html/index.html (30.05.2016)

$21 \mathrm{Vgl}$. Österreichisches Biographisches Lexikon und biographische Dokumentation http://www. biographien.ac.at/oebl/oebl_B/Berzeviczy_Albert_1853_1936.xml (30.05.2016)

22 Zwar entwickelte sich parallel dazu auch eine kleine Gruppe der sozialistischen Avantgarde, deren wichtigster Vertreter Lajos Kassák war, allerdings blieb ihr Einfluss beschränkt. Vgl.: Rónay, László: Die Avantgarde. In: Ders.: Abriß der ungarischen Literaturgeschichte. Budapest 1997, S. 209-214 sowie Csorba, Csilla; Veronika Baksa-Soós: Lajos Kassák. Botschafter der Avantgarde 1915 - 1927. Budapest 2011

23 Siehe dazu 4.2 Magyar Corvin Lánc und Magyar Corvin Koszorú, S. 188

$24 \mathrm{http} / / / w w w . i r o d a l m i j e l e n . h u / 05242013-0959 /$ herczeg-ferenc (30.05.2016)

25 Vgl. Onagy, Zoltán: Herczeg Ferenc. In: Irodalmi Jelen. http://www.irodalmijelen.hu/052420130959/herczeg-ferenc (11.08.2016)

26 Vgl. Zeidler, Miklós: Irredentism in Everyday Life in Hungary during the Inter-war Period. In: Regio - Minorities, Politics, Society - English Edition. 1 (2002), S. 71-88 sowie ausführlicher in ungarischer Sprache: Zeidler, Miklós: A revíziós gondolat. Pozsony [Bratislava] 2009

27 Dávid, Gyula (Hg.): Romániai magyar irodalmi lexikon: Szépirodalom, közírás, tudományos irodalom, művelődés 4. (N-R). Bukarest 2003, S. 617

28 Der Name der Zeitschrift sollte als Programm dienen: „Wir wollten, dass dieser Titel an sich selbst schon ein Programm sein soll. Es ist ein genauer Ausdruck unseres Zieles. Unser Ziel [...] ist die Bewahrung der ungarischen Traditionen, die Weiterentwicklung des ungarischen Gefühls, der ungarischen Gedanken auf der Basis der ungarischen Traditionen, und der Kampf, wenn es sein muss gegen all solche Gefühle und all solche Gedanken, die von diesen fremd sind.“ Diese Erläuterung findet sich im Leitartikel der ersten Ausgabe der Zeitschrift, die am 9. Jänner 1921 unter der Redaktion von Reményik erschien. Vgl. Bokor, Gizella; Anna BokorKiss: Pásztortüz repertórium 1921-1944. http://pasztortuz.adatbank.transindex.ro/?extra=2 (14.05.2016)

29 Vgl. Murányi 1999, S. 101

30 Für sämtliche biographischen Angaben zu Cecile Tormay siehe: Kádár, Judit: Tormay Cecile (1875-1937): a Horthy-korszak ünnepelt írónője. In: Dies.: Engedelmes lázadók. Magyar írónők és nőideál-konstrukciók a 20. század első felében. Pécs 2014, S. 57-82

31 Eine Reihe von historischen Fehlern als auch die statische Perspektive der Tagebuchschreiberin machen deutlich, dass es sich bei dem Bujdosó könyv nicht um ein authentisches Tagebuch handelt, sondern um einen nachträglich als solches verfassten Text. Nichtsdestotrotz wurde das Buch von der Leserschaft als authentisches Zeitdokument rezipiert, das den Zusammenbruch der Monarchie, die Räterepublik und deren Scheitern dokumentierte. Tatsächlich handelt es sich um ein politische Überzeugungen propagierendes Werk, das durch die Form des Tagebuchs durch die vermeintliche Augenzeugenperspektive den Anschein der Objektivität vermitteln will. Vgl. Kádár 2014, S. 60 f

32 Der Verband war eine der wichtigsten ideologischen Stützen des Horthy-Regimes. 1921 zählte der Verband bereits mehr als eine Million Mitglieder und verfügte über 400 Filialen am Land. Hinter der vordergründigen Propagierung sozialer Reformen, spielte der Verband in erster Linie in der politischen Agitation, der Vernetzung der mittelständischen Frauen sowie der ideologischen Beeinflussung von Frauen aus niedereren sozialen Schichten sowie der Jugend eine tragende Rolle. Vgl. Kádár 2014, S. 73

33 Genauso sank nicht zuletzt auch das literarische Niveau von Herczegs Új Idök, da sich auch ihr politischer Charakter wandelte: ihre ideologische Bindung zum Illusionismus der Mittelschicht 
wurde offenkundig als sie ebenso zum Sprachrohr des ungehemmten chauvinistischen Irredentismus wurde. Vgl. Kókay / Oltványi 1978, S. 308

34 Diesen hatte sie auch die Auflösung eines rund um Tormay entbrannten Skandals im Jahr 1925 zu verdanken: Bei der Scheidung von Graf Rafael Zichy und Gräfin Edina Pallavicini bezichtigte der Graf im Zuge der Gerichtsverhandlungen seine Frau, ein Liebesbeziehung mit Cecile Tormay zu unterhalten. Der Vorwurf erregte große Aufmerksamkeit in den Medien, die Gräfin und die Schriftstellerin sahen sich gezwungen eine Verleumdungsklage gegen den Grafen einzureichen. Auf offensichtlichen politischen Druck hin wurde der Graf schließlich zu eineinhalb Jahren Gefängnis verurteilt, um die Reputation von Tormay zu schützen. Tatsächlich bestehen allerdings bis dato Vermutungen, dass Tormay homosexuell war, zumal sie bereits vor der Gräfin Zichy eine enge Verbindung zu Francesca D’Orsay pflegte und auch ihre letzten Lebensjahre gemeinsam mit Gräfin Ambrózy-Migazzi Lajosné in einer Villa in Mátraháza verlebte. Letztere war es auch, die Tormays gesammelte Werke posthum herausgab. Vgl. Kádár 2014, S. $79 f$

35 Für sämtliche biographischen Angaben zu Irén Gulácsy siehe: Balogh, Edgár (Hg.): Romániai magyar irodalmi lexikon: Szépirodalom, közírás, tudományos irodalom, müvelődés 2. (G-Ke). Bukarest 1991, S. 211

36 Ab 1919 war Berde Mitglied der Erdélyi Irodalmi Társaság (Siebenbürger Literarische Gesellschaft), ein Jahr später auch der Kemény Zsigmond Társaság (Zsigmond Kemény Gesellschaft) sowie Redakteurin bei den Zeitschriften Erdélyi Szemle (Siebenbürger Rundschau), Zord Idök (Rauhe Zeiten) und Napkelet. Sie propagierte bereits früh die Gründung einer Arbeitsgemeinschaft freier siebenbürgischer Schriftsteller, was sie allerdings erst 1933 insofern verwirklichen konnte, als sie gemeinsam mit Lajos Olosz, István Szombati-Szabó und Géza Tabéry den EMÍR - Erdélyi Magyar Írói Rend (Siebenbürgischer Ungarischer Schriftstellerorden) gründete, zu dem auch ein Verlag gehörte, in dem sie bis 1937 tätig war.

37 Siehe dazu Lilla Bolemants Studie über Berdes Roman: Bolemant Lilla: A szent szégyen (tanulmány) - Irodalmi Szemle Online. http:/www.irodalmiszemle.bici.sk/lapszamok/2013/2013marcius/1599-bolemant-lilla-a-szent-szegyen-tanulmany (24.05.2016)

38 „Sie vertrat jene intellektuelle Schicht Siebenbürgens, die sich zwar nicht auf die Seite der Arbeiterbewegung schlug, sich aber auch weder zur Zeit seines Vorstoßes noch zur Zeit seines Höhepunktes während der Kriegsphase gegen die Sowjetunion von der Ideologie des Faschismus verführen ließ. Und mit ihren eigenen Mitteln bezog sie auch Stellung, als sie angesichts des Faschismus ihren Zeitgenossen in ihrem 1942 erschienenen Roman die großen Gestalten des Reformzeitalters, die hajnal emberei (Menschen der Morgendämmerung) präsentiert, die gegen die Willkürherrschaft, gegen rassistische und religiöse Vorurteile und für den Gedanken der Freiheit kämpfen.“ - Balogh 1991, S. 211

39 Für sämtliche Zahlenangaben den wachsenden Buchmarkt betreffend siehe: Romsics 2005, S. 211

40 Romsics 2005 S. 212 